\title{
Kurse der Schweizerischen Ärztegesellschaft für Akupunktur - Chinesische Medizin - Aurikulomedizin
}

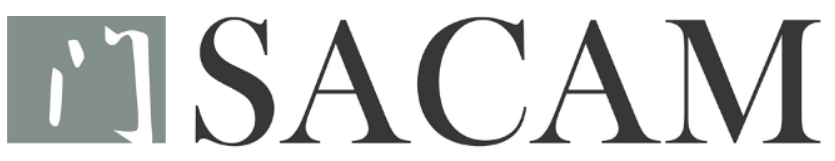

SCHWEIZERISCHE ÄRZTEGESELLSCHAFT FÜR AKUPUNKTUR - CHINESISCHE MEDIZIN - AURIKULOMEDIZIN

Akupunktur Fachtagungsreihe: Bern

15.01.2022 Neurologie

19.02.2022 HNO und Sinnesorgane:

04.\&05.\&12.03.2022 Lehrgang Ohrakupunktur/RACkontrollierte Akupunktur 2 (Fortgeschrittene): Stufe 6 Bern Emotionalfeld-Akupunktur, die Linie der Infekte Akupunktur-Fachtagungsreihe: Bern 19.03.2022 Verdauung 09.04.2022 Bewegungsapparat

06.\&07.05.2022 Lehrgang Ohrakupunktur/RAC-kontrollierte Akupunktur 2 (Fortgeschrittene): Prüfungsvorbereitung Bern

11.06.2022 ASA-Modulprüfungen

Bern

(Terminänderungen vorbehalten)

Weitere Informationen entnehmen Sie bitte den Ausschreibungen auf der Homepage der sacam: www.sacam.ch Ärztebereich - Weiter- und Fortbildung

\section{Geschäftsstelle:}

SACAM I gkaufmann Verbandsmanagement \& Kongressorganisation Wattenwylweg 21 3006 Bern (Schweiz)

Tel. 0844200200

Fax 0313324112 info@sacam.ch www.sacam.ch 